\title{
An integrated process for the production of lignocellulosic biomass pyrolysis oils using calcined limestone as a heat carrier with catalytic properties
}

\author{
A. Veses, M. Aznar, M.S. Callén, R. Murillo, T. García* \\ Instituto de Carboquímica (ICB-CSIC), C/Miguel Luesma 4, 50018 Zaragoza, Spain.
}

\begin{abstract}
The production of upgraded bio-oils by an integrated process using a mixture of calcined limestone and sand as a heat carrier with catalytic properties was experimentally studied at pilot scale. The integrated process consisted of two main steps: biomass catalytic pyrolysis in an Auger reactor for bio-oil production and char combustion in a fluidised-bed combustor for heat carrier heating and regeneration. A temperature of $450^{\circ} \mathrm{C}$ was fixed as an optimum value to carry out the catalytic pyrolysis step. Temperatures ranging from 700 to $800^{\circ} \mathrm{C}$ were assessed in the char combustor. Process simulation demonstrated that solid recirculation from the combustor to the pyrolysis reactor was marginally affected in this temperature range. However, an optimum char combustion temperature of $800{ }^{\circ} \mathrm{C}$ was selected from an environmental point of view, since lower polyaromatic emissions were detected whilst NOx emissions were kept under the legislation limits. Under designated conditions, several pyrolysis-combustion cycles were carried out. A moderate deactivation of the catalyst by partial carbonation was found. This fact makes necessary the incorporation of a purge and an inlet of fresh heat carrier in order to maintain the bio-oil quality in the integrated process.
\end{abstract}

Keywords: Biomass; catalytic pyrolysis; char combustion; Auger reactor, fluidised-bed reactor. 
*Corresponding author: Tomás García. Email: tomas@icb.csic.es. Phone: +34 976 733977, Fax: +34 976733318

\section{Introduction}

Considering the increase on the demand of energy, new clean and renewable sources are emerging in order to minimize the environmental impact associated to the use of fossil fuels. Valorisation of lignocellulosic biomass from pyrolysis process is in increasing research, becoming one of the most promising thermo-chemical conversion technologies [1]. Pyrolysis allows the conversion of biomass into value-added chemicals and potential fuels in the form of gas, solid and especially in the form of liquid. This liquid, also called bio-oil, presents higher energy density than solid biomass and can be easily stored and transported, making it a good potential candidate to be used as a new sustainable energy vector [1],[2]. Although there are several activities taking some steps forward in the commercialization of bio-oil for energy applications [3], its use as a fuel is limited due to its specific properties. Thus, its high oxygen content, its remarkable acidic character and its chemical instability [4] makes it difficult to be applied directly in power generation. As a result, the bio-oil needs to be upgraded in order to make it suitable for current infrastructures.

There are several technologies relying on bio-oil upgrading which are trying to eliminate the oxygen-containing molecules by increasing the $\mathrm{H} / \mathrm{C}$ ratio, being in situ catalytic pyrolysis one of the most promising. It is well known that the reactor design and the proper selection of the catalysts play a fundamental role in this kind of technology. Ideally, the

catalysts employed should be highly active, selective to particular products, resistant to 
deactivation, readily recycled and whenever possible, cheap and widely distributed. Although different and relatively high value catalysts have been tested for biomass catalytic pyrolysis, including microporous zeolites, mesoporous M41S and mesoporous aluminosilicates [5],[6], some low-cost catalysts such as bulk metal oxides [7], sulphide/oxide, alumina, metals supported mainly on alumina [8], clay materials [9] or industrial wastes, such as red mud [9],[10], have also been tested with relative success for biomass catalytic pyrolysis.

In order to evaluate the industrial prospects of the biomass pyrolysis, the use of Auger type reactors can be highlighted [11],[12]. This type of reactors has a simple design that allows the user to work with low carrier gas flow and with large biomass particles showing an excellent reproducibility and stability [13],[14]. Moreover, they are easy-scalable and can be applicable for small, medium and portable pyrolysis systems in distributed or decentralised areas. In this type of reactors, where the heat input is indirect, the use of a heat carrier at commercial scales is very recommendable in order to provide the required high rates of heat transfer [15]. Indeed, several authors [15], [16] working on an Auger reactor using heat carriers without catalytic properties, have already reported liquid yields quite similar (75 wt.\%) to those obtained by flash pyrolysis on fluidised-bed reactors. In this line, some of the main companies in the field, such as ABRI-tech in Canada, LurgiRuhrgas process in Germany or Renewable Oil Intel in USA have already implanted large scale Auger reactors [4]. Although there are several advantages at industrial scales, little research has been carried out on the performance of an Auger reactor on the catalytic pyrolysis of biomass [17]. Thus, this raises an attractive investigation field. 
Several layouts for the pyrolysis process have also been proposed to reach a global selfsustainable performance from an energetic point of view [3], [18], [19]. In a previous work developed in our group, both oxygen content and acidity of bio-oils were found to decrease in woody biomass pyrolysis carried out in an Auger reactor when low-cost materials, such as $\mathrm{CaO} /$ sand or $\mathrm{CaO} \cdot \mathrm{MgO} /$ sand mixtures, were used as both in situ catalysts and heat carriers [20]. Moreover, the self-sustainable performance of the pyrolysis system (operating at $450^{\circ} \mathrm{C}$ ) followed by the char combustion process (operating at about $800^{\circ} \mathrm{C}$ ) was theoretically demonstrated from an energetic standpoint. The process simulation demonstrated that the circulation of solids between the pyrolysis and the combustor reactor was the lowest using $\mathrm{CaO} /$ sand mixture. In that work, the pyrolysis step was also experimentally tested in a pilot-scale Auger reactor for a certain $\mathrm{CaO}$ to biomass ratio but the performance of the char combustion step and its influence on the overall process was not carried out. Herein, a fluidised-bed reactor is proposed as an appropriate technology to carry out this step, since it would facilitate both the solids transport in the system and the char total combustion [21]. Besides, this type of combustor would be a suitable technology for the energetic use of biomass char because of its advantages in terms of reduction of pollutant emissions and flexibility [22].

Therefore, the initial objective of this work is to study experimentally the char combustion process in a fluidised-bed combustor at temperatures ranging from $700-800{ }^{\circ} \mathrm{C}$, using a $\mathrm{CaO}+$ sand mixture as heat carrier with catalytic properties. After that, a study of the performance of the integrated system during cyclic operation was carried out.

\section{Material and methods}

\subsection{Biomass and materials}


The biomass used in the present study was forest pine woodchips (Pinus halepensis) containing bark, obtained from north-east area of Spain (Ansó, Huesca) and was supplied by AFPURNA S.L. The fresh biomass was first dried up to moisture levels lower than $2 \mathrm{wt}$. $\%$ and then was milled and sieved providing a maximum nominal size of $15 \mathrm{~mm}$. The lower heating value (LHV) of the biomass was $18.0 \mathrm{MJ} / \mathrm{kg}$ (measured experimentally with a calorimetric bomb IKA C-2000 using the standard procedure UNE 164001 EX). Proximate analysis of the received biomass showed a moisture percentage of 4.0 wt.\% (ISO-5891981), ash proportion of 1.1 wt.\% (ISO-1171-1976), volatile matter of 78.6 wt.\% (ISO5623-1974), while fixed carbon was 16.3 wt.\% (determined by balance). Ultimate analysis of the received biomass showed a composition of C: 49.6 wt.\%, H: 6.4 wt.\%, N: 0.2 wt.\%, S: $<0.1$ wt.\% (by Thermo flash 1112, UNE EN 5104) and O: 43.8 wt.\% (by balance). Biomass was initially dried up to $<2$ wt.\% moisture. Silica-based sand and calcined calcite (90\% CaO, Calcinor) were also used in this work. $\mathrm{CaO}$ was commercially available and obtained after calcination of calcite at $900{ }^{\circ} \mathrm{C}$. Silica-based sand particle size distribution was in the range of 200-600 $\mu \mathrm{m}$ and particle size distribution for $\mathrm{CaO}$ was in the range of 300-600 $\mu \mathrm{m}$. Pyrolytic char was obtained from biomass pyrolysis process at $450^{\circ} \mathrm{C}$ using the Auger reactor facility previously described.

\subsection{Simulation process}

Aspen Hysys simulation software was used to simulate the process. The layout was based on the self-sustainable biomass pyrolysis system proposed in a previous work [20], where $\mathrm{CaO} /$ sand mixture was proposed as a heat carrier with catalytic properties. Process simulation allowed determining the different operational parameters in the char fluidisedbed reactor to carry out the combustion process at different temperatures $\left(700{ }^{\circ} \mathrm{C}, 750{ }^{\circ} \mathrm{C}\right.$ and $800^{\circ} \mathrm{C}$ ) whilst maintaining the biomass catalytic pyrolysis parameters at the optimal 
conditions [20]. Under these conditions, the overall simulation process determined the solids circulating from the pyrolysis reactor to the combustor, which can be modified by the amount of inert sand circulating in the integrated process.

\subsection{Auger reactor experiments}

Pyrolysis experiments were conducted in an Auger reactor plant of $100 \mathrm{~kW}_{\text {th }}$ of nominal capacity for woody biomass. A detailed description of the reactor can be found elsewhere [9],[23]. The experiments were carried out at atmospheric pressure, continuously feeding biomass and a mixture of sand and $\mathrm{CaO}$ as heat carrier. Pyrolysis process was conducted under the optimal operating conditions achieved in the previous study: pyrolysis temperature: $450^{\circ} \mathrm{C}$; biomass mass flow: $2 \mathrm{~kg} / \mathrm{h}$; solid residence time: $7 \mathrm{~min}$; biomass to $\mathrm{CaO}$ ratio of 3:1; heat carrier (sand $+\mathrm{CaO}$ ) to biomass ratio of 3:1; and $\mathrm{N}_{2}$ as inert gas (100 $\mathrm{ml} / \mathrm{min}$ ). Non catalytic tests working with sand were also conducted for comparative purposes. Once the bio-oil and the solid products were recovered, their respective yields were calculated directly by weight. The gas yield was calculated from the $\mathrm{N}_{2}$ percentage in the gas stream, which was used as an internal standard to quantify the outside gas production. It should also be noted that the mass balance closed at $100 \pm 5 \%$. It is worth noting that three replicate runs were carried out for the non-catalytic pyrolysis test and using $\mathrm{CaO}$ as catalyst, showing similar liquid, solid and gas yields with acceptable experimental error (lower than $5.0 \%$ ).

\subsection{Fluidised-bed reactor experiments}

The combustion of the solid mixture composed of char and heat carrier was carried out in a fluidised-bed reactor. The system comprises a $3 \mathrm{~m}$ length tubular stainless steel reactor with an inner diameter of $150 \mathrm{~mm}$, including a freeboard of $200 \mathrm{~mm}$. The temperature and the 
pressure were monitored by several thermocouples and pressure transducers disposed along the reactor. Downstream the reactor, two high-efficiency cyclones and two heat exchangers were located in order to adequate the gas stream both for separating the suspended particles and for collecting the condensed water, respectively. The volume of gas generated was measured by means of a vortex-type gas counter located at the final section. Finally, the non-condensable gas stream was conducted to a burner before leaving the experimental system to the atmosphere. A scheme of the fluidised-bed reactor pilot plant is shown in Figure 1.

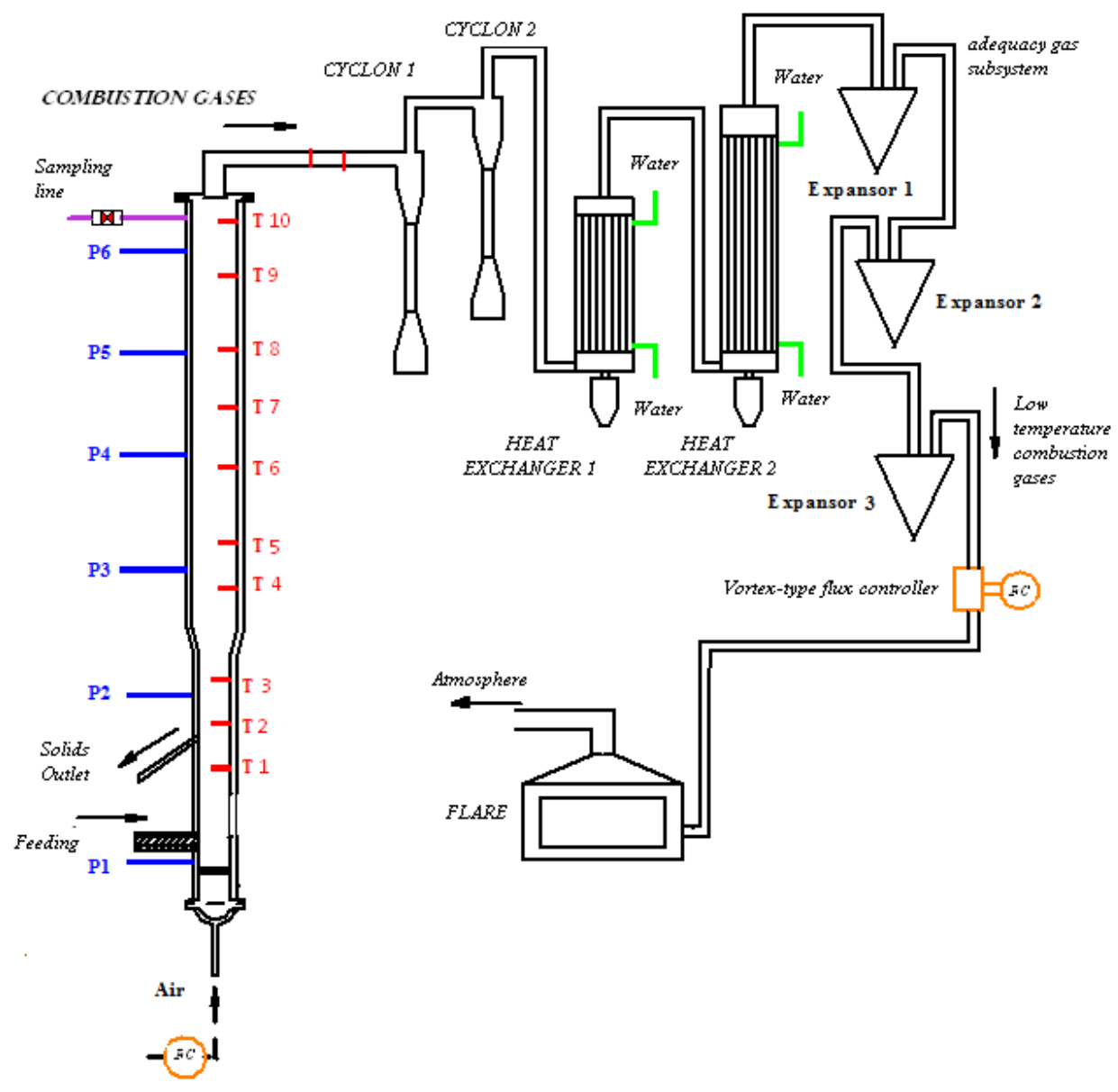

Figure 1. Fluidised-bed reactor pilot-scale scheme. 
Initially, the performance of the fluidised-bed combustor was carried out by preparing mixtures of sand, $\mathrm{CaO}$ and pyrolytic biomass char and subsequently were burnt with 20 vol.\% of air excess. The lower heating value (LHV) of the pyrolytic char was $29.1 \mathrm{MJ} / \mathrm{kg}$ (measured experimentally with a calorimetric bomb IKA C-2000 using the standard procedure UNE 164001 EX). Proximate analysis of the pyrolytic char showed a moisture percentage of 6.1 wt.\% (ISO-589-1981) and ash proportion of 3.5 wt.\% (ISO-1171-1976. Ultimate analysis of the pyrolytic char showed a composition of C: 76.4 wt.\%, H: 3.9 wt.\%, N: 0.1 wt.\%, S: $<0.1$ wt.\% (by Thermo flash 1112, UNE EN 5104) and O: 19.6 wt.\% (by balance). Several temperatures from $700-800{ }^{\circ} \mathrm{C}$ were tested. Ratios of char to heat carrier at the different temperatures were determined according to the results obtained from the simulation process. Several tests working with merely sand as heat carrier were also simulated. Considering a particle size distribution between 0.2 and 0.6 , fluidization velocity was ensured to be maintained in the range of $0.32-0.36 \mathrm{~m} / \mathrm{s}$, fulfilling the limitations of the terminal velocity to the full range of particles. Under these conditions, gas residence time was estimated to be in the range of 1.3 - $1.5 \mathrm{~s}$. It is worth noting that three replicate runs were carried out for the non-catalytic pyrolysis test by using sand as a heat transfer, showing similar emissions with acceptable experimental error.

\subsection{Experimental procedure for cycling operation}

In order to study the self-sustained system, several tests comprising both, the biomass catalytic pyrolysis in the Auger pilot plant and the char combustion in a fluidised-bed reactor, were carried out. Once accomplished, the heat carrier $($ sand $+\mathrm{CaO})+$ ash mixture was recovered and recirculated to the pyrolysis facility, completing one whole cycle. This process was performed three times. For each experiment, product characterization was 
carried out as the following section describes.

\subsection{Product characterization}

\subsubsection{Pyrolysis gas characterization}

Non-condensable gases were analysed by GC/TCD (HP 5890-Series II) using Molsieve $5 \AA$ and Hayesep Q columns. The analysed compounds were $\mathrm{H}_{2}, \mathrm{~N}_{2}, \mathrm{CH}_{4}, \mathrm{CO}, \mathrm{CO}_{2}, \mathrm{C}_{2} \mathrm{H}_{6}$, $\mathrm{C}_{2} \mathrm{H}_{4}$ and $\mathrm{C}_{3} \mathrm{H}_{8}$.

\subsubsection{Bio-oil characterization}

Bio-oil obtained as a heterogeneous liquid was separated in two different phases. The whole sample was centrifuged at $1500 \mathrm{rpm}$ for $1 \mathrm{~h}$ and the aqueous and organic phases were subsequently collected by decantation. In order to characterize the organic liquid fraction, considered the best potential as a renewable stock to be used in a bio-refinery, some physicochemical properties such as $\mathrm{pH}$, total acid number (TAN) and water content were measured and, the calorific value and the ultimate analysis were also determined. Finally, a semi-quantitative approach of the chemical composition of bio-oil was determined by GC/MS. A widely description about the process carried out has been added as Supporting Information.

\subsubsection{Measurement of the heat carrier carbonation}

The experimental procedure was conducted as follows in a thermobalance SETARAM Setsys. First, the sample was heated $\left(30^{\circ} \mathrm{C} / \mathrm{min}\right)$ in $\mathrm{N}_{2}$ atmosphere up to $900^{\circ} \mathrm{C}$ and kept for 10 minutes. The sample was cooled down to $650^{\circ} \mathrm{C}$ and then was kept at the same temperature for 10 minutes in $\mathrm{N}_{2} / \mathrm{CO}_{2}(85 \% / 15 \%)$ atmosphere. Finally, the sample was heated $\left(30^{\circ} \mathrm{C} / \mathrm{min}\right)$ in $\mathrm{N}_{2}$ atmosphere up to $900^{\circ} \mathrm{C}$ and kept for 10 minutes.

\subsubsection{Combustion gas characterization and polycyclic aromatic hydrocarbons (PAH) trapping system}


On-line characterization of the combustion gases was carried out by a TESTO 350 XL analyzer situated downstream of the fluidised-bed combustion pilot plant exhaust. $\mathrm{O}_{2}, \mathrm{CO}$, $\mathrm{CO}_{2}, \mathrm{NO}_{\mathrm{x}}$ and $\mathrm{SO}_{2}$ were analyzed. At the same point, a flow sampling system was installed to capture PAH emissions. The used trapping system was formed by: a quartz filter (47 mm diameter) to determine particulate phase $\mathrm{PAH}$ followed by two connected steel tube cartridges (gas phase PAH) packed with 1.5 grams of XAD-2 resin and supported by quartz wool. The resins system was kept at $120^{\circ} \mathrm{C}$ in order to avoid water condensation. Previous to the sampling, filters and XAD-2 resins were Soxhlet extracted with DCM for 24 hours to remove potential contaminants during the analytical method. $\mathrm{PAH}$ were quantified according to previous publications using a gas chromatography mass spectrometry mass spectrometry (GC-MS-MS) technique [24],[25]. A detailed description of the PAH analysis was provided as Supporting Information, Table S1.

\section{Results and discussion}

\subsection{Operational parameters}

Aspen Hysys simulation software was used to determine the process parameters of the integrated system required to operate the fluidised-bed reactor at different combustion temperatures. These parameters using either merely silica-based sand or $\mathrm{CaO} /$ sand mixture as heat carriers are shown in Table 1 . It is worth commenting that $650^{\circ} \mathrm{C}$ was initially ruled out as a potential char combustion temperature since, at this conditions, the carbonation reaction of $\mathrm{CaO}$ to $\mathrm{CaCO}_{3}$ would be favoured [26], likely deactivating the catalytic properties of the heat carrier for the subsequent pyrolysis step. In Table 1, it is shown that the inventory of solids required in the integrated system was lower using a $\mathrm{CaO} / \mathrm{sand}$ mixture as heat carrier. This result is in line with previously published data [20], showing 
that the incorporation of $\mathrm{CaO}$ as heat carrier with catalytic properties favoured the energetic integration of the process. Additionally, Table 1 pointed out that whilst the demand of heat carrier to be recirculated into the pyrolysis reactor using a CaO/sand mixture as heat carrier was hardly affected by the char combustion temperature (from $700^{\circ} \mathrm{C}$ to $800^{\circ} \mathrm{C}$ ), fluidisedbed reactor temperature had a significant influence in the inventory of solids to be recirculated using merely sand as heat carrier.

Table 1. Process parameters in the integrated process obtained from Aspen Hysys simulation. Pyrolysis reactor: Temperature: $450{ }^{\circ} \mathrm{C}$; Biomass mass flow: $2 \mathrm{~kg} / \mathrm{h}$.

\begin{tabular}{|c|c|c|c|c|c|}
\hline \multicolumn{3}{|c|}{ Sand } & \multicolumn{3}{|c|}{ CaO+Sand } \\
\hline $\begin{array}{c}\mathbf{T}_{\text {Comb }}{ }^{a} \\
\left({ }^{\circ} \mathrm{C}\right)\end{array}$ & $\begin{array}{c}\text { Ratio } \\
\text { Carrier/Biomass }\end{array}$ & $\begin{array}{c}\text { Feeding }^{\mathrm{a}} \\
(\mathrm{kg} / \mathrm{h})\end{array}$ & $\begin{array}{c}\mathbf{T}_{\text {Comb }}{ }^{\mathrm{a}} \\
\left({ }^{\circ} \mathrm{C}\right)\end{array}$ & $\begin{array}{c}\text { Ratio } \\
\text { Carrier/Biomass }\end{array}$ & $\begin{array}{c}\text { Feeding }^{\mathrm{a}} \\
(\mathrm{kg} / \mathrm{h})\end{array}$ \\
\hline 800 & 3.7 & 8.2 & 800 & 2.7 & 6.2 \\
\hline 750 & 4.3 & 9.3 & 750 & 3.0 & 6.7 \\
\hline 700 & 5.1 & 11.0 & 700 & 3.4 & 7.7 \\
\hline
\end{tabular}

\subsection{Char combustion in fluidised-bed reactor}

Combustion of char and heat carrier (either sand or $\mathrm{CaO}+$ sand) mixtures were performed in the range of $700-800{ }^{\circ} \mathrm{C}$ as previously explained in Section 2.2. Under those conditions, pollutant emissions were on-line analysed. Turning on to the results obtained, it can be mentioned that $\mathrm{SO}_{2}$ emissions were not detected, as expected, according to the very low $\mathrm{S}$ content in the biomass. Regarding the $\mathrm{NO}_{\mathrm{x}}$ emissions showed in Fig. 2A, it can be highlighted that both, the emissions produced when $\mathrm{CaO}$ was co-fed and also those produced when merely sand was used, were under the limits permitted according to the legislation for emissions from medium combustion plants using biomass (500 mg/ $\mathrm{Nm}^{3}$, at 6 vol.\% $\mathrm{O}_{2}$, for new plants of 1-5 $\mathrm{MW}$ and $300 \mathrm{mg} / \mathrm{Nm}^{3}$ at 6 vol.\% $\mathrm{O}_{2}$ for plants of 5-50 MW) [27] and even taking into account the more restrictive legislation for larger 
combustion plants (250 mg/ $\mathrm{Nm}^{3}$ at 6 vol.\% $\mathrm{O}_{2}$ ) [28].

$\mathrm{NO}_{\mathrm{x}}$ formation is a complex process affected by numerous parameters, such as combustion temperature, fuel chemical properties, devolatilisation conditions and the mixture between fuel and oxidiser [29],[30],[31]. At the studied temperature range, it can be assumed that the formation of thermal $\mathrm{NO}_{\mathrm{x}}$ was not relevant since temperature values were well below to those that could promote thermal $\mathrm{NO}_{\mathrm{x}}$ (around $1500{ }^{\circ} \mathrm{C}$ in the flame) [21].The formation of $\mathrm{NO}_{\mathrm{x}}$ from biomass is not only temperature sensitive, but also largely dependent on the $\mathrm{N}$ content of the char, its reactivity and the available oxygen concentration at the initial combustion sections of the furnace [32],[33]. In line with this, results plotted in Fig. 2A did not show relevant differences in $\mathrm{NO}_{\mathrm{x}}$ emissions with temperature variation for the catalytic and non-catalytic tests. Thus, $\mathrm{NO}_{\mathrm{x}}$ emissions can be mainly related to char composition. Comparing sand and $\mathrm{CaO}+$ sand runs, it can be stated that the presence of $\mathrm{CaO}$ slightly increased NOx emissions. This negative effect can be explained taking into account the potential reducing effect of char over $\mathrm{NO}_{\mathrm{x}}$ by catalysing the $\mathrm{NO}$ reduction by $\mathrm{CO}$ [34]. In agreement with this, a lower $\mathrm{CO}$ production (Fig.2B) was observed in the $\mathrm{CaO}+$ sand experiments.

Regarding $\mathrm{CO}$ emissions, it has been reported that several parameters that could control its formation include temperature, particle size, residence time and mixing efficiency [31]. CO emissions are mainly due to incomplete combustion and belong to the category of unburned pollutants [21]. As can be observed in Fig. 2B, very low CO concentrations were emitted at each temperature. For both series (sand and $\mathrm{CaO}+$ sand), it was observed that $\mathrm{CO}$ emission profiles showed a minimum at $750^{\circ} \mathrm{C}$. It is noteworthy that $\mathrm{CO}$ emissions observed at lower temperature were marginally higher, probably due to a slightly poorer combustion of the char. Likewise, slightly higher CO concentrations were also emitted at $800^{\circ} \mathrm{C}$. At this 
process conditions, the gas velocity in the reactor was increased, which could favour the elutriation of fine char particles before their complete oxidation, preventing the total fuel combustion and conversion into $\mathrm{CO}_{2}$ and $\mathrm{H}_{2} \mathrm{O}$.

Moreover, $\mathrm{CaO}$ incorporation to the heat carrier exerted a noteworthy positive effect on the $\mathrm{CO}$ emissions. The lower $\mathrm{CO}$ emissions observed when $\mathrm{CaO}$ was present could be likely due to a certain enhancement of shift reaction, caused by $\mathrm{CO}_{2}$ capture by calcium-based materials. This effect was more relevant at the lower temperatures where carbonation was favoured. In any case, the contribution of $\mathrm{CO}$ conversion to $\mathrm{CO}_{2}$ production was marginal due to the very low CO concentrations (below 0.1 vol.\%).

Finally, PAH emissions were also determined for each temperature by measuring its emissions during the stationary step of the experiments, as it has been detailed in Section 2.6.4 and in the Supporting Information. A detailed description of the evolution of the PAH individual compounds can also be found in the Supporting Information (Tables S2-S4). The more abundant compounds were naphthalene and phenanthrene. It is worth commenting that the concentration of naphthalene was rather high compared to the other compounds. This result was in line with published data since naphthalene has been usually reported as a major product of pyrolysis and incomplete combustion processes [35],[36]. It is generally accepted that the formation of PAHs entails a very complex mechanism. Briefly, a possible route could be the incomplete combustion, causing the emission of fragments of the char aromatic structures. A correlation between $\mathrm{PAH}$ and $\mathrm{CO}$ emissions appears when this mechanism is prevalent. Another possibility is the pyrolysis and pyrosynthesis route, coming from polymerization reactions of radicals formed during char devolatilisation [37],[38],[39]. It is worth commenting that although the biomass particles were previously pyrolysed, a non-negligible amount of volatile matter was still present in the char (30 wt. \% 
approximately) because of the mild pyrolysis temperatures. Therefore, these volatiles can be released as radicals during the initial steps of the char combustion process that takes place at higher temperature than pyrolysis and, eventually, lead to PAH formation. Accordingly, PAH emission profiles with the char combustion temperature should be explained taking into account both routes for PAH formation, radical pyrosynthesis and char incomplete combustion.

Fig. 2C shows the evolution of the PAH emissions with respect to the temperature. Firstly, the contribution of the incomplete combustion route was assessed. Both series (either sand or $\mathrm{CaO}+$ sand tests) showed a maximum at $750{ }^{\circ} \mathrm{C}$, being those $\mathrm{PAH}$ emissions found at either $700^{\circ} \mathrm{C}$ or $800^{\circ} \mathrm{C}$ significantly lower. Clearly, this emission pattern cannot be directly correlated to an incomplete char combustion process since the lowest $\mathrm{CO}$ emissions were produced at $750^{\circ} \mathrm{C}$. This fact could suggest that the contribution of the char incomplete combustion route to the PAH emissions profile was not the prevalent mechanism and that the pyrosynthetic route should have a predominant role.

At the top of the reactor, where the radical interactions were produced [37], PAH formation by the pyrosynthetic route was significantly influenced by the gas residence time. At 700 ${ }^{\circ} \mathrm{C}$, it could be expected that a longer residence time of the radicals could facilitate their total oxidation. Accordingly, low PAH emissions were detected at these experimental conditions (see Figure 4C). As the char combustion temperature was further increased up to $750{ }^{\circ} \mathrm{C}$, volatiles residence time was decreased. Thus, it could be assumed that radical total oxidation could become more difficult [40], promoting PAH formation and release. Accordingly, it was observed that the formation of light gas-phase PAH (with 2-3 aromatic rings), both in solid and gas phase, was strongly promoted. This result could also be in line with a lower gas residence time, decreasing the probability of radical interactions and 
preventing the formation of high molecular weight PAHs. Finally, total PAH emissions were surprisingly reduced at $800^{\circ} \mathrm{C}$. At this temperature, only solid phase PAHs emissions trapped in the filter were mostly detected in the exhaust gases. This fact could be tentatively linked to a lower probability for radical interactions, which might promote the formation of volatile organic compounds lighter than PAHs. The formation of this type of non-refractory compounds, which could be burned easier, might explain the decreased PAH emissions observed under these experimental conditions. Additionally, it cannot be completely ruled out that the elutriation of char aromatic fragments could have a role on the total PAH emissions found for the sand test at $800^{\circ} \mathrm{C}$. Accordingly, a different emission pattern was found for this experiment, since it was observed that PAH with four or more aromatic rings accounted for 90 wt. \% of the total PAH emissions, which is in line with the fact that CO emissions significantly increased at $800^{\circ} \mathrm{C}$. For the $\mathrm{CaO}+$ sand test, it was observed that although $\mathrm{CO}$ emissions were also increased at $800^{\circ} \mathrm{C}$, overall $\mathrm{PAH}$ emissions were reduced; especially those related to PAHs with four or more aromatics rings, which only accounted for 4 wt. \% of the total PAHs emissions. A cracking effect of the $\mathrm{CaO}$ could explain this scenario. Indeed, it is worth highlighting that total PAH emissions were significantly reduced incorporating $\mathrm{CaO}$ as heat carrier in the whole temperature range. As can be observed in Fig.2C, total PAH detected in the $\mathrm{CaO}+$ sand tests decreased about 35\% at $700^{\circ} \mathrm{C}, 60 \%$ at $750{ }^{\circ} \mathrm{C}$ and $50 \%$ at $800^{\circ} \mathrm{C}$ with respect to the sand tests, being the lowest emissions obtained at $800^{\circ} \mathrm{C}$. Additionally, some subtle differences were also found in the PAH emission partitioning between the solid and gas phase depending on the nature of the heat carrier, see Fig. 2D. Thus, whilst PAH emissions were mostly detected in the filter (as solid phase) for the $\mathrm{CaO}+$ sand tests, $\mathrm{PAH}$ emissions in the gas phase were a significant fraction of the total PAH emissions for the sand tests, except at $800{ }^{\circ} \mathrm{C}$. This behaviour 
could be related to the presence of porous calcined limestone where PAH adsorption could be produced. Therefore, it can be stated that the incorporation of $\mathrm{CaO}$ to the heat carrier had two positive effects on the PAH emissions. Firstly, a cracking effect, since the total amount of PAH emissions was significantly decreased [41] and, secondly, an adsorbent effect, since PAH emissions were mostly retained in the solid phase by means of the $\mathrm{CaO}$ porosity. As result, it can be concluded that the incorporation of calcined limestone as heat carrier to the integrated process could help to control PAH emissions by using modern particulate matter emissions-control equipment. This conclusion agrees with previously reported results for PAH emissions related to coal combustion [42]. In summary, $800{ }^{\circ} \mathrm{C}$ was selected as the optimum temperature since PAH emissions were minimised without significantly affecting $\mathrm{CO}$ and NOx emissions, compared to those obtained at lower temperatures. Besides, at this temperature, the complete calcination of $\mathrm{CaCO}_{3}$ in the combustor would be practically ensured, according to equilibrium from Baker [26] and considering an acceptable margin of around 0.05 atm between equilibrium $\mathrm{CO}_{2}$ partial pressure and $\mathrm{CO}_{2}$ partial pressure at the combustor exit [43] 

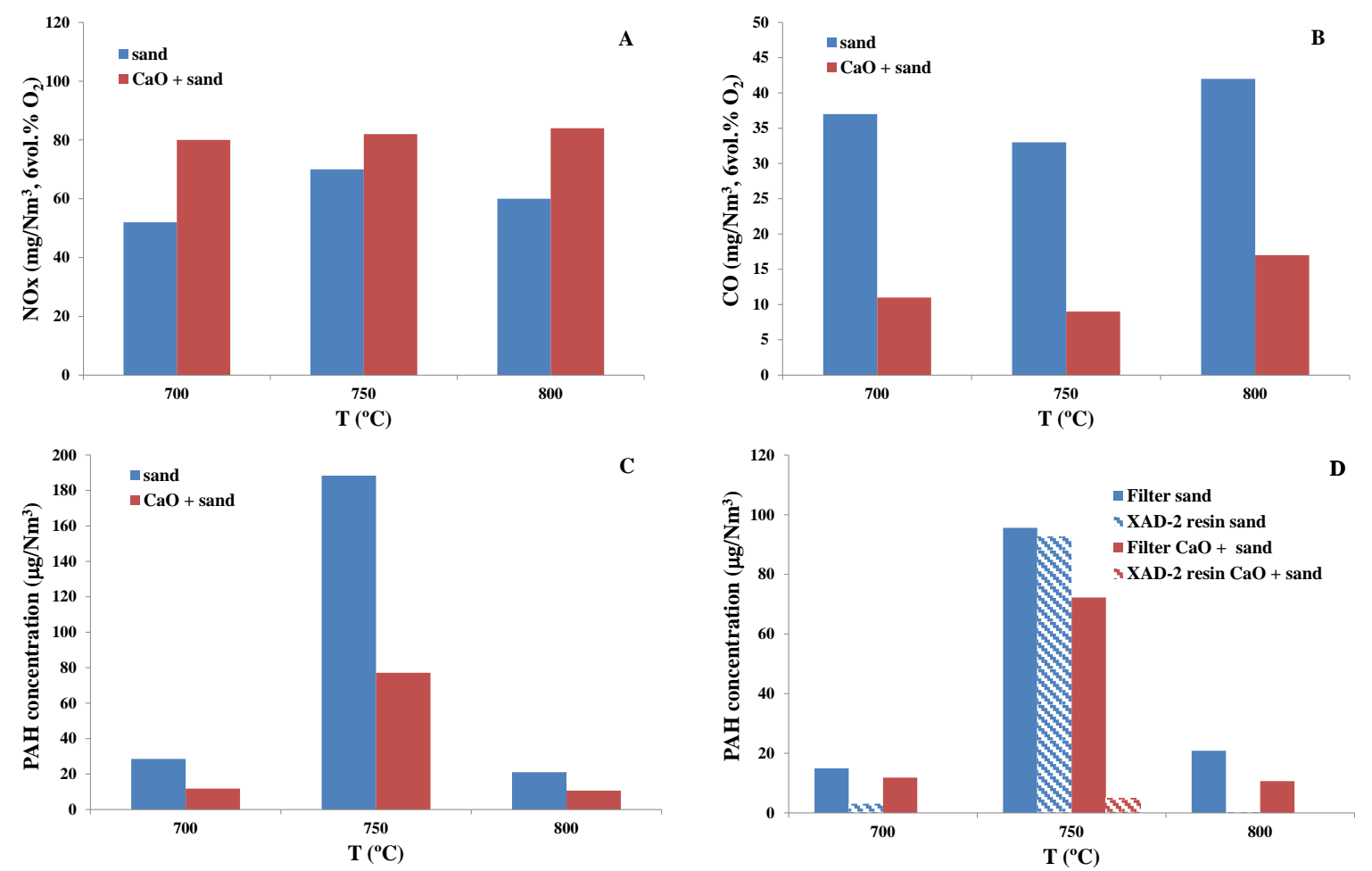

Figure 2. (A) $\mathrm{NO}_{\mathrm{x}}$ emissions (mg/ $/ \mathrm{Nm}^{3}, 6$ vol.\% $\left.\mathrm{O}_{2}\right)$, (B) CO emissions (mg $/ \mathrm{Nm}^{3}, 6$ vol.\% $\mathrm{O}_{2}$ ) and (C) and (D) Distribution of PAH emissions $\left(\mu \mathrm{g} / \mathrm{Nm}^{3}\right)$ between quartz filter (solid phase) and XAD-2 resins (gas phase) in the combustion process of biomass char and heat carrier mixtures.

\subsection{Catalytic pyrolysis cycles using $\mathrm{CaO}+$ sand as heat carrier}

Several catalytic pyrolysis-combustion cycles were performed in order to assess the influence of the cyclic process on the yields and quality of the products obtained after catalytic pyrolysis steps. According to previous data, a char combustion temperature of $800^{\circ} \mathrm{C}$ was fixed. Table 2 points out that the liquid, solid and gas yields showed comparable values, about 46, 25 and 27 wt. \%, respectively, after three pyrolysis-combustion consecutive cycles. Unfortunately, some differences were found in the yield to organic phase. Thus, a continuous decrease after cycling operation from 37 to 33 wt. \% was observed, which could be related to a promotion of dehydration reactions during the 
upgraded process. Additionally, fuel properties of this organic phase were also analysed and reported in Table 2. Whilst $\mathrm{pH}$ value was reduced from 4.2 to 3.5, as the process cycles were conducted, oxygen content was increased and, in turn, a poorer calorific value was obtained. Chemical composition determined by a semi-quantitative analysis by GC/MS was in line with the higher acidity and the decreasing deoxygenation rate (see Table 2 and Table S5 Supporting Information). Thus, it can be observed that as cycles were conducted, not only the relative amount of aromatic compounds and ketones decreased, but also other undesired oxygenate compounds, such as acids and aldehydes, increased. Indeed, chemical composition of the bio-oil tended to that composition found for the non-catalytic biomass pyrolysis experiment. These results clearly evidenced that a deactivation of the $\mathrm{CaO}$ catalysts was taking place.

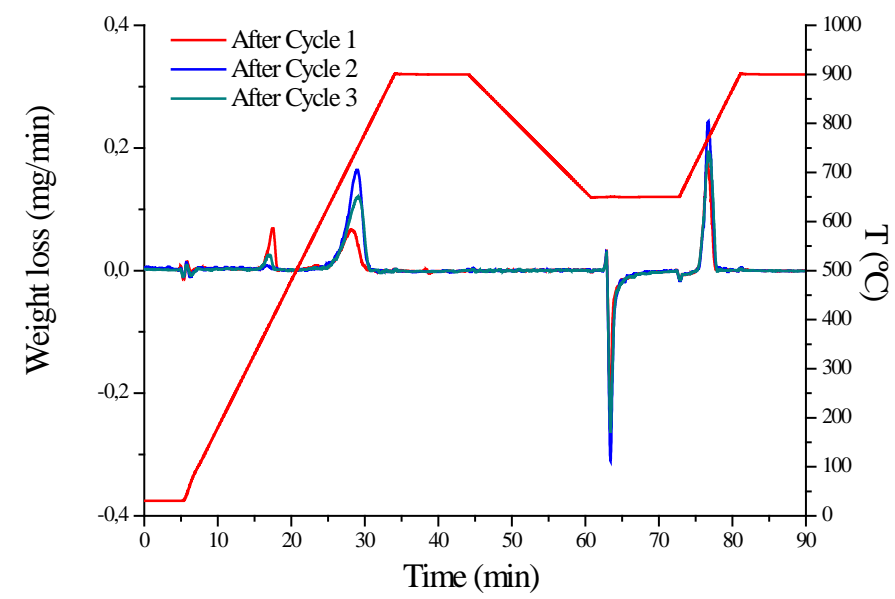

Figure 3. Thermogravimetric analysis of $\mathrm{CaO}$ (fresh and used after the different pyrolysiscombustion cycles). 
Table 2. Product yields, fuel properties, chemical composition and gas composition obtained after three cycles of catalytic pyrolysis using $\mathrm{CaO}+$ sand mixtures as heat carrier with catalytic properties. Non-catalytic test (sand) is attached for comparative purposes.

\begin{tabular}{|c|c|c|c|c|}
\hline \multirow[b]{2}{*}{ Yields } & \multicolumn{4}{|c|}{ Pyrolysis experiment } \\
\hline & Cycle 1 & Cycle 2 & Cycle 3 & Non-Catalytic \\
\hline Liquid (wt. \%) & 46.5 & 45.8 & 46.1 & 45.8 \\
\hline Gas (wt. \%) & 24.2 & 25.6 & 25.3 & 26.5 \\
\hline Solid (wt. \%) & 27.6 & 26.9 & 27.5 & 26.7 \\
\hline Organic phase (wt. \%) & 37.9 & 36.2 & 33.1 & 27.0 \\
\hline \multicolumn{5}{|l|}{ Fuel properties } \\
\hline $\mathbf{H}_{2} \mathbf{O}$ (wt. \%) & 14.4 & 15.9 & 16.0 & 13 \\
\hline pH & 4.2 & 3.4 & 3.5 & 2.9 \\
\hline TAN $(\mathrm{mg} \mathrm{KOH} / \mathrm{g})$ & 32.5 & 35.2 & 36.4 & 70.0 \\
\hline HHV $(M J / k g)$ & 29.6 & 27.5 & 24.7 & 22.4 \\
\hline \multicolumn{5}{|l|}{ Ultimate analysis } \\
\hline $\mathbf{C}(w t . \%)$ & 67.6 & 66.2 & 63.4 & 60.6 \\
\hline $\mathbf{H}(w t . \%)$ & 8.2 & 8.1 & 8.0 & 7.7 \\
\hline $\mathbf{N}(w t . \%)$ & 0.17 & 0.2 & 0.4 & 0.2 \\
\hline $\mathbf{S}(w t . \%)$ & $<0.1$ & $<0.1$ & $<0.1$ & $<0.1$ \\
\hline $\mathbf{O}(w t . \%)$ & 24.0 & 25.5 & 28.2 & 31.5 \\
\hline $\mathbf{O} / \mathbf{C}(\mathrm{mol} / \mathrm{mol})$ & 0.3 & 0.3 & 0.4 & 0.5 \\
\hline $\mathbf{H} / \mathbf{C}(\mathrm{mol} / \mathrm{mol})$ & 1.3 & 1.5 & 1.5 & 1.5 \\
\hline \multicolumn{5}{|l|}{ Chemical composition } \\
\hline Phenols (area \%) & 48.5 & 44.2 & 46.6 & 51.5 \\
\hline Acids (area \%) & 4.1 & 6.4 & 6.7 & 7.1 \\
\hline Aldehydes (area \%) & 3.1 & 7.2 & 6.7 & 6.2 \\
\hline Furans and Furfurals (area \%) & 4.0 & 8.0 & 8.0 & 12.7 \\
\hline Ketones (area \%) & 14.1 & 11.7 & 10.6 & 8.7 \\
\hline Cyclic-HC (area \%) & 4.1 & 3.5 & 3.6 & 3.6 \\
\hline Aromatic-HC (area \%) & 15.5 & 12.9 & 12.4 & 5.1 \\
\hline Levoglucosan $^{\text {a }}$ (area \%) & 0.7 & 1.4 & 1.4 & 1.4 \\
\hline Esters (area \%) & 4.4 & 4.4 & 3.8 & 3.3 \\
\hline \multicolumn{5}{|c|}{ Gas composition (free of $\mathrm{H}_{2} \mathrm{O}$ and $\mathrm{N}_{2}$ ) } \\
\hline $\mathbf{H}_{2}(\mathrm{vol} . \%)$ & 11.9 & 5.6 & 5.0 & 2.9 \\
\hline CO (vol.\%) & 40.2 & 43.6 & 42.5 & 39.3 \\
\hline $\mathrm{CO}_{2}(\mathrm{vol} . \%)$ & 27.2 & 31.7 & 34.2 & 42.9 \\
\hline $\mathbf{C H}_{4}$ (vol.\%) & 12.1 & 11.7 & 11.2 & 9.3 \\
\hline $\mathbf{C}_{2} \mathbf{H}_{4}($ vol. $\%)$ & 2.4 & 3.2 & 3.1 & 1.8 \\
\hline $\mathbf{C}_{2} \mathbf{H}_{6}$ (vol.\%) & 2.5 & 2.3 & 2.2 & 1.7 \\
\hline $\mathbf{C}_{3} \mathbf{H}_{8}$ (vol.\%) & 2.4 & 2.0 & 1.9 & 2.1 \\
\hline LHV $\left(M J / N m^{3}\right)$ & 14.0 & 16.5 & 15.8 & 12.7 \\
\hline
\end{tabular}

${ }^{a}$ : Not included in their chemical class. HC: Hydrocarbons

In order to clarify this deactivation process, a semi-quantitative thermogravimetric experiment of the heat carrier mixture obtained after the combustion step was carried out. In this experiment, an initial decarbonation step up to $900^{\circ} \mathrm{C}$ in $\mathrm{N}_{2}$ atmosphere was 
followed by a carbonation stage at $650^{\circ} \mathrm{C}\left(20 \mathrm{vol} . \% \mathrm{CO}_{2}\right.$ in $\left.\mathrm{N}_{2}\right)$ and a final decarbonation step in $\mathrm{N}_{2}$ atmosphere up to $900^{\circ} \mathrm{C}$. These thermograms, added in Fig. 3 showed the evolution of several peaks. The first peak about $400^{\circ} \mathrm{C}$ can be related to the dehydration of calcium hydroxide. It can be observed how the intensity of this peak was significantly decreased and almost disappeared after three cycles. A lower $\mathrm{CaO}$ hydration capacity with the number of cycles was in line with the increasing proportion of water phase obtained in the upgraded bio-oil. Figure 3 also showed a second broad peak with the maximum located at approximately $725-750{ }^{\circ} \mathrm{C}$, which can be tentatively assigned to the decarbonation of limestone. This peak area remarkably increased after the first and the second cycle and, then, decreased after the third cycle, suggesting that $\mathrm{CaCO}_{3}$ decarbonation was not complete after the char combustion stage. Surprisingly, it was observed that the area of this peak was significantly higher than the one obtained after a subsequent carbonation step and that its initial loss of mass was shifted to lower temperature. These features could be related to the presence of some organic compounds strongly adsorbed on the $\mathrm{CaO}$ porosity, as previously commented. Therefore, it can be concluded that partially carbonated and saturated $\mathrm{CaO}$ seemed to be recirculated to the pyrolysis reactor after the combustion process, clearly modifying the catalytic properties of the heat carrier. This conclusion was in line with the differences found in the gas stream composition after the catalytic pyrolysis experiments as showed in Table 2. Thus, it can be observed that $\mathrm{CO}_{2}$ and $\mathrm{H}_{2}$ compositions were slightly modified, increasing the $\mathrm{CO}_{2}$ concentration and, on the contrary, decreasing the $\mathrm{H}_{2}$ concentration. $\mathrm{CO}_{2}$ capture, promoted in this case by $\mathrm{CaO}$, which simultaneously favours $\mathrm{H}_{2}$ production from water gas shift reaction and the methane reforming reaction, was slightly reduced and in turn, the catalytic role of $\mathrm{CaO}$ during the upgrading process could be negatively affected. Hence, it can be stated that the reaction of "the active quasi- 
$\mathrm{CO}_{2}$ intermediates” with the partially carbonated $\mathrm{CaO}$ could be also hindered, which has been reported as one of the preferred path of catalytic upgrading reactions during biomass catalytic pyrolysis using calcium-based sorbents [7],[20]. Additionally, it cannot be totally ruled out that heat carrier composition was varied during cycling operation, increasing sand to $\mathrm{CaO}$ ratio and in consequence, slightly decreasing the bio-oil quality. This could be explained by the difference on the physical properties between sand and $\mathrm{CaO}$. The porous nature of $\mathrm{CaO}$, together with its lower relative density with respect to sand and the attrition phenomena produced, could produce some changes on the distribution of the mixture due to elutriation of $\mathrm{CaO}$ particles with the gas stream. Likewise, ash biomass content after char combustion could be another parameter leading to a decreasing $\mathrm{CaO}$ proportion in the heat carrier. Therefore, all these factors could explain the deactivation observed for the catalytic properties of the heat carrier during cyclic operation, which ranged from 8 to $10 \%$ per cycle for each of the different bio-oil properties reported in Table 2.

Against this background, it can be concluded that it would be necessary to incorporate both a purge and an inlet of fresh heat carrier $(\mathrm{CaO}+$ sand $)$ in order to keep on the stability of the catalytic pyrolysis process. To analyse the effect of these modifications on the performance of the simulated integrated process during cyclic operation, a basis for comparison of 5 ton/h of biomass (with 30 wt.\% of moisture content) was assumed. The influence of the purge on the amount of electricity generated was evaluated whilst the other process outputs during bio-oil production were maintained. It can be observed that the electricity generation process is marginally affected by the amount of purge, and net electricity produced only decreased from 1.57 to $1.52 \mathrm{MWe}$ for 1 ton/h of fresh heat carrier fed to the combustion reactor, which accounted for $9 \%$ of the total amount of heat carrier circulated in the integrated process. 
Finally, it is worth commenting that although the use of calcined calcite has been shown very promising results, further research should be carried out in order to find more active catalyst during cyclic operation. Moreover, the addition of plastics promoters could be an interesting approach to increase the quality of the pyrolytic bio-oils.

\section{Conclusions}

Biomass catalytic pyrolysis and char combustion tests were performed in an Auger reactor pilot plant and in a fluidised-bed reactor pilot plant, respectively. It was demonstrated that a self-sustained process entailing pyrolysis and combustion processes using calcined limestone and sand mixtures as heat carrier with catalytic properties, could be successfully integrated in order to obtain an upgraded bio-oil. Solid recirculation between pyrolysis and combustion reactors was marginally influenced by char combustion reactor temperature. A combustion temperature of $800^{\circ} \mathrm{C}$ seemed to be the optimum value from an environmental point of view, not only keeping the emission values of NOx under the limit established by legislation but also providing lower PAH emissions in the gas combustion stream. Finally, a moderate deactivation of the catalyst by partial carbonation was found after the char

combustion experiments. This scenario would imply the incorporation of both a purge and an inlet of fresh heat carrier $(\mathrm{CaO}+$ sand) in order to keep the quality of the bio-oil obtained during the catalytic pyrolysis process. This purge slightly decreased the energetic integration of the proposed process from 1.57 to $1.52 \mathrm{MWe}$ for 1 ton/h of fresh heat carrier fed to the combustion reactor, which accounted for $9 \%$ of the total amount of heat carrier circulated in the integrated process.

\section{Acknowledgements}


Authors thank to Spanish MINECO and European Union FEDER funds for providing support for this work (projects CTQ2012-37984-C02-01 and ENE2015-68320-R).

\section{References}

[1] Bridgwater AV. Biomass fast pyrolysis. Thermal Science 2004;8(2):21-49.

[2] Czernik S, Bridgwater AV. Overview of Applications of Biomass Fast Pyrolysis Oil. Energy Fuels 2004;18(2):590-598.

[3] Meier D, Van Der Beld B, Bridgwater AV, Elliot DC, Oasmaa A, Preto F. State-of-theart of fast pyrolysys in IEA bioenergy member countries. Renew Sustain Energy Rev 2013;20:619-641.

[4] Bridgwater AV. Review of fast pyrolysis of biomass and product upgrading. Biomass Bioenergy 2012;38:68-98.

[5] Taarning E, Osmundsen CM, Yang X, Voss B, Andersen SI, Christensen CH. Zeolitecatalyzed biomass conversion to fuels and chemicals. Energy Environ Sci 2011;4:793804.

[6] Perego C, Bosetti C. Biomass to fuels: the role of the zeolite and mesoporous materials. Microporous Mesoporous Mater. 2011;144:28-39.

[7] Lin Y, Zhang C, Zhang M, Zhang J. Deoxygenation of bio-oil during pyrolysis of biomass in the presence of $\mathrm{CaO}$ in a fluidised-bed reactor. Energy Fuels 2010;24:56865695.

[8] Bulushev DA, Ross JRH. Catalysis for conversion of biomass to fuels via pyrolysis and gasification: a review. Catal Today 2011;171:1-13. 
[9] Veses A, Aznar M, López JM, Callén MS, Murillo R, García T. Production of upgraded bio-oils by biomass catalytic pyrolysis in an Auger reactor using low cost materials. Fuel 2015;141:17-22.

[10] Yathavan BK, Agblevor FA. Catalytic pyrolysis of pinyon-juniper using red mud and HZSM-5. Energy Fuels 2013;27:6858-65.

[11] Mohan D, Pittman CU, Steele PH. Pyrolysis of wood/biomass for Bio-oil: A critical review. Energy Fuels 2006;20:848-889.

[12] Papari S, Hawboldt K. A review on the pyrolysis of woody biomass to bio-oil: Focus on kinetic models. Renew Sustain Energy Rev 2015;52:1580-1595.

[13] Puy N, Murillo R, Navarro MV, López JM, Rieradevall J, Fowler G, Aranguren I, García T, Bartrolí J, Mastral AM. Valorisation of forestry waste by pyrolysis in an Auger reactor. Waste Manage 2011;31:1339-1349.

[14] Ingram I, Mohan D, Bricka M, Steele P, Strobel D, Mitchell B, et al. Pyrolysis of Wood and bark in an Auger reactor: physical properties and chemical analysis of the produced bio-oils. Energy 2008;22:614-625.

[15] Brown JN, Brown RC. Process optimization of an Auger pyrolyzer with heat carrier using response surface methodology. Bioresour Technol 2012;103:405-414.

[16] Liaw SS, Zhou S, Wu H, García-Pérez M. Effect of pretreatment temperature on the yield and properties of bio-oils obtained from the Auger pyrolysis of Douglas fir Wood. Fuel 2013;103:672-682.

[17] Yildiz G, Pronk M, Djokic M, Van Geem KM, Ronsse F, Van Duren R, et al. Validation of a new set-up for continuous catalytic fast pyrolysis of biomass coupled with vapor phase upgrading. J Anal Appl Pyrol 2013;103:343-351. 
[18] Xu R, Ferrante L, Briens C, Berruti F. Bio-oil production by flash pyrolysis of sugarcane residues and post treatments of the aqueous phase. J Anal Appl Pyrol 2011:91; 263-272.

[19] Yildiz G, Ronsse F, van Duren R, Prins W. Challenges in the design and operation of processes for catalytic fast pyrolysis of woody biomass. Renew Sustain Energy Rev 2016; 57:1596-1610.

[20] Veses A, Aznar M, Martínez I, Martínez JD, López JM, Navarro MV, Callén MS, Murillo R, García T. Catalytic pyrolysis of wood biomass in an Auger reactor using calcium-based catalysts. Bioresour Technol. 2014;162:250-258.

[21] Khan AA, de Jong W, Jansens PJ, Spliethoff H. Biomass combustion in fluidised bed boilers: Potential problems and remedies. Fuel Process Technol 2009;90:21-50.

[22] Pereira CC, Pinho C. Determination of Fluidised Bed Combustion Kinetic and Diffusive Data of Four Wood Chars from the Central Region of Portugal. Energy Fuels 2013;27:7521-7530.

[23] Martínez JD, Murillo R, García T, Veses A. Demonstration of the waste tire pyrolysis process on pilot scale in a continuous Auger reactor. J Hazard Mater 2013;261:637645.

[24] Callén MS, de la Cruz MT, López JM, Murillo R, Navarro MV, Mastral AM. Some inferences on the mechanism of atmospheric gas-particle partitioning of PAH at Zaragoza (Spain). Chemosphere 2008;73:1357-1365.

[25] Callén MS, López JM, Mastral AM. Apportionment of the airborne PM10 in Spain. Episodes of potential negative impact for human health. J Environ Monit 2012;14:1211-1220. 
[26] Baker R. The reversibility of the reaction $\mathrm{CaCO}_{3} \leftrightarrow \mathrm{CaO}+\mathrm{CO}_{2}$. J Appl Chem Biotechnol 1973;23:733-742.

[27] Directive EU 2015/2193.

[28] Directive EU 2010/75.

[29] Glarborg P, Jensen AD, Johnsson JE. Fuel nitrogen conversion in solid fuel fired systems. Prog Energy Combust Sci 2003;29(2):89-113.

[30] Di-Nola G, De-Jong W, Spliethoff H. TG-FTIR characterization of coal and biomass single fuels and blends under slow heating rate conditions: partitioning of the fuelbound nitrogen. Fuel Process Technol 2010;91:103-115.

[31] Bartolomé C, Gil A. Emissions during co-firing of two energy crops in a PF pilot plant: Cynara and poplar. Fuel Process Technol 2013;113:75-83.

[32] Tillman DA. The combustion of solid fuels and wastes. Academic Press, San Diego, 1991.

[33] Kaynak B, Topal H, Atimtay AT. Peach and apricot stone combustion in a bubbling fluidised bed. Fuel Process Technol 2005;86:1175-1193.

[34] Permchart W, Kouprianov VI. Emission performance and combustion efficiency of a conical fluidised-bed combustor firing various biomass fuels. Bioresour Technol 2004;92:83-91.

[35] Williams PT, Taylor DT, Horne PA. Polycyclic aromatic hydrocarbons in polystyrene derived pyrolysis. J Anal Appl Pyrol 1993;25:325-334.

[36] Jenkins BM, Jones DA, Turn SQ, Williams RB. Particle concentrations, gas-particle partitioning, and species intercorrelations for Polycyclic Aromatic Hydrocarbons (PAH) emitted during biomass burning. 1996. Atmospheric Environment 1996;30:3825-3835. 
[37] Mastral AM, Callén MS, Murillo R. Assessment of PAH emissions as a function of coal combustion variables. Fuel 1996;75:1533-1536.

[38] Tuominen J. Determination of Polycyclic Aromatic Hydrocarbons by Gas Chromatography/Mass Spectrometry and Method Development in Supercritical Fluid Chromatography, Publication 60, Technical Research Centre of Finland, Espoo, 1990.

[39] Flagan RC, Seinfeld JH. Fundamentals of Air Pollution Engineering, Prentice-Hall, Englewood Cliffs, NJ, 1988.

[40] Mastral AM, Callén MS, Murillo R, García T. Combustion of high calorific value waste material. Organic atmospheric pollution. Combustion of high calorific value waste material. Organic atmospheric pollution. Environ Sci Technol 1999;33:41554158.

[41] Abu El-Rub Z, Bramer EA, Brem G. Review of Catalysts for tar elimination in biomass gasification process. Ind Eng Chem Res 2004;43:6911-6919.

[42] Mastral AM, Garcia T, Callén MS, López JM, Murillo R, Navarro MV. Effects of Limestone on Polycyclic Aromatic Hydrocarbon Emissions during Coal Atmospheric Fluidised Bed Combustion. Energy Fuels 2001;15(6):1469-1464.

[43] Martínez I, Grasa G, Murillo R, Arias B, Abanades JC. Kinetics of calcination of partially carbonated particles in a Ca-looping system for $\mathrm{CO}_{2}$ capture. Energy Fuels 2012;26:1432-1440. 